\title{
Culture and Mental Health: A Review of Culture related Psychiatric Conditions
}

\author{
S Karthick ${ }^{1 *}$ and Sangita Barwa ${ }^{2}$ \\ ${ }^{1}$ Department of Humanities and Liberal Arts in Management, Indian Institue of Management Kozhikode, India \\ ${ }^{2}$ Department of Humanities and Social Sciences, National Institute of Technology Rourkela, India
}

Submission:August 08, 2017; Published: August 23, 2017

*Corresponding author: S Karthick, Department of Humanities and Liberal Arts in Management, Indian Institute of Management Kozhikode, Kozhikode-673570, Kerala, India, Tel: +91-9688442205, Email: skc.karthick@gmail.com

\begin{abstract}
Culture is the characteristics of human behavior and knowledge of a particular group of people, encompassing speech, action, and artifacts. Culture has its primary psychological influence on issues of identity and it is a keystone in psychiatry, and also it is an abstract, reflecting the total way of life of a society. This article discusses the concept of culture and its relation with mental health conditions. In mental health problems, from presentation of illness to course and outcome, at every stage are influenced by cultural issues. Researchers and available literature listed that the range of psychiatric condition in the diagnoses of cultural bound syndrome and the importance of cultural aspects in psychiatric diagnosis. The impact of culture on specific syndromes that are strongly related to culture is easier to be seen. However, it needs to be recognized that culture-related mental health conditions are merely the tip of the iceberg. The diverse cultural and ethnicity of the world is a challenge to the field of mental health towards the development of cross culture approach. Therefore the focus should not be on the clinical manifestation but the evaluations should be made from the view of cultural aspects too.
\end{abstract}

Keywords: Culture; Mental Health; Psychiatric Conditions; Culture Bound Syndrome

\section{Introduction}

Culture is defined as the total pattern of human behavior and its products embodied in speech, action, and artefacts which dependent upon people's capacity for learning and transmitting knowledge to succeeding generations [1]. Thus culture entails a set of values, ideas, beliefs and attitudes. It establishes relationships between social being and even between the living and the dead (especially in Africa). In Ghana, for example it is believed that the dead are still "alive" but in a different form (spirit) from where they now have "super control" over what goes on in their absence.

They can reward the faithful and punish the unfaithful. However, culture is not static; it grows out of a systematically encouraged relevance for selected customs and habits [2]. Culture has its primary psychological influence on issues of identity. The central psychological consequence of individual is that it results in transformations in identity, that is, how people think about themselves in relation to the social environment. First, as a consequence of westernization, most people in the world now develop a bi-cultural identity, in which part of their identity is rooted in their local culture while another part stems from an awareness of their relation to the global culture. Second, the pervasiveness of identity confusion may be increasing among young people in non-Western cultures. As local cultures change in response to globalization, some young people find themselves at home in neither the local culture nor the global culture [3].

'Culture', which is a keystone in psychiatry, is an abstraction, reflecting the total way of life of a society. Culture is best conceptualized as a totality, composed of a complex system of symbols possessing subjective dimensions such as values, feelings, and ideals and objective dimensions including beliefs, traditions, and behavioral prescriptions, articulated into laws and rituals. This unique capacity of culture to bind the objective world of perceived reality to the subjective world of the personal and intimate, lends it, its powerful role as expresser, mediator, and moderator of psychological processes and, ultimately, mental disorders [4]. Mental health problems, from presentation 
of illness to course and outcome, at every stage are influenced by cultural issues.

\section{Culture's Contribution To Mental Health}

\section{Cultural Variations of Family Systems}

Changes in any one member of the system will influence the whole family system as each member of the family plays an important role in the system to act as a unit. Kinship system, family structure, primary axis, interpersonal-dynamics, oneparent family, and family violence are important psychologically.

\section{Child Development and Enculturation Process}

The upbringing process of the child, cultural rituals and ethics in which the child was brought up, gender-based customs, schooling, childhood trauma or abuse- all have significant impact on personality development.

\section{Social Customs}

Habitual ways of behaving carried out by tradition and enforced by social sanctions-like customs relating to exposure of body parts, food choices, sexuality, and substance abuse/ drinking, social interaction and restrictions.

\section{Rituals}

It can be described as actions which are done primarily for their symbolic value [5].

\section{Etiquette}

It is the social behavior which is accepted according to conventional norm within a society or a group.

\section{Taboos}

A socially prohibited things or behavior. In every culture there are some superstitious beliefs and set rules of avoidance of some behaviors or objects breaching of which is not accepted socially.

\section{Culture and Gender}

Different cultures differentiate and define roles based on biological sex and reproductive functions. Men and women have some fundamentally different experiences of their bodies, of their social worlds and of their life course.

\section{Beliefs about Health-Illness-Healing}

Culture influences the illness beliefs and thus enhances 'psychic infectivity' in some psychiatric epidemics. Beliefs about witchcraft, evil spirits etc. greatly influences the illness of the person [6].

\section{Value System}

Values influence on how we think and behave. They are a significant part of culture, where they form a part of the shared rule-set of a group. If someone transgresses other's value it may lead to betrayal responses (distress, loss of trust and seeking justice).

\section{Idioms of Distress}

Culture influences people's understanding and their response to distressing events. Expression of distress is different in different cultures or communities.

\section{Disease and Illness}

Disease is a biological construct and represents all the manifestations of ill health in response to some pathological process and is translated into nosological descriptions of signs/ symptoms. Illness, a socio-cultural construct, have a symbolic nature, and it is primarily represented by the subjective, emotional, behavioral, interpretative and communicative responses of the affected individual.[5] Cultural explanation and ethno medical worldview influence the perception of illness and health, healing and sick role and illness behavior [7].

\section{Explanatory Model of Illness (EMI)}

Patient's belief about the illness influence their symptom formation and degree of disability. Klienman suggested that by exploring the explanatory model of illness we can better understand our patients and families [8].

\section{Experiences With The Cultural System}

Enculturation is the process by which a person learns the appropriate values and behaviors of his culture through childrearing patterns, language development, and institutionalized education and through different abiding social systems. Acculturation is a process in which members of one cultural group adopt the cultural traits or social patterns of another group. Acculturation is an important process of cultural change in immigrated population and it influences their mental health [9].

\section{Acculturative Stress}

The psychological, somatic and social difficulties which accompanies the acculturation processes. This may involve serious changes in multiple areas of functioning (e.g., values, behaviors, beliefs, attitudes, etiquette, moral judgment etc.), and for individuals, families, and groups engaged in this process, these adjustments can be stressful.

\section{Assimilation}

When a minority group adapts to the customs and values of the prevailing culture. It is a two-way process where at first an individual or a group of diverse ethnic and racial minority or immigrant individuals comes to adopt the beliefs, values, attitudes, and the behaviors of the majority or dominant culture and secondly they discard the value system of their cultural tradition and become a member of the dominant society. This is however a slow and a gradual process.

\section{Deculturation or Cultural Uprooting}

When a member of non-dominant cultures become alienated (either by accident or by force) from the dominant culture 
and from their own minority society [10]. The consequence of deculturation may results in increased stress and psychopathology and cultural bereavement $[11,12]$.

\section{Cultural diffusion}

It is the spreading of ideas or products from one culture to another. This concept was first introduced by Krober [13]. There are three categories of cultural diffusion: Direct diffusion, forced diffusion and indirect diffusion. Intermarriage, trade, Colonization is some of the examples. Through technological advancements, media, TV, movies, culture may be transmitted to people far away without any direct contact.

\section{Diaspora}

It is the movement, migration, or scattering of people away from an established or ancestral homeland .The term Diaspora carries a sense of displacement and a sense of hidden hope or desire to return to homeland

\section{Cultural Paranoia}

The concept was introduced by Grier \& Cobbs in their book 'Black Rage', where they said that Black clients may not disclose personal information to White therapists for fear that they may be vulnerable to racial discrimination and this condition was regarded not a form of psychopathology but a healthy and adaptive response by African Americans towards the white Americans [14].

\section{Cultural Mistrust}

It refers to the situation when one race is not able to trust the people of another race.

\section{Culture shock}

When people of one culture have to adapt to a new one for a short period of time and they are not able to cope with it. Cultural confusion is the initial phase of cultural shock when they are not able to deal with the new situation.

\section{Cultural Accommodation}

When individual accept the culture of the host and carry it out too in public domain while maintaining their own culture in a privately.

\section{Cultural Negotiation}

Cultural negotiation takes place in individual, interpersonal and systemic level where one negotiate with the culture depending on the environment [15].

\section{Culture Bound Syndrome}

The term culture bound was used in the past to describe patterned behaviors of distress or illness whose phenomenology appeared distinct from psychiatric categories and were considered unique to particular cultural settings. In the modern sense, culture-bound syndrome is an inherited and controversial term that can be used at present to describe forms of psychopathology on whose emergence, manifestation or course local cultural factors exert an especially strong influence. [16] In this period of rapid globalization, and cultural factors are becoming more diffuse and easily accessible. Thus, the relevance of the culture and culture bound syndrome is changing.

According to Hughes and colleagues the phenomena of the culture-bound syndromes do not form discrete, bounded entities that can translate into conventional Western categories but are present amongst the various established diagnostic entities encompassing the numerous parts of the DSM nosological structure $[16,17]$.

The culture-bound syndromes coexist with a range of psychiatric disorders. Differences in the symptomatic, emotional, and contextual aspects of cultural syndromes signal either different comorbid relationships with psychiatric diagnosis or even the lack of such a relationship. E.g. the identification of subtypes of ataque de nervios help in formation of its relationship with psychiatric disorders: persons experiencing more dissociative phenomena during their attacks, such as passing out or amnesia, showed increased tendency to meet the criteria for a comorbid psychiatric diagnosis [18].

\section{Culture-Bound Syndromes in The Diagnostic Manuals}

The rise of culture-bound syndromes may be a reflection of the rise of Western diagnostic and classificatory systems, along with the long-standing impact of colonialism. The two major psychiatric classificatory systems have used these syndromes in slightly different ways. Recent shifts in the DSM-5, however, may indicate a change away from these factors [19]. The ICD-10 recognizes a number of culturally uncommon symptom patterns and presentations, referred to as "culture-specific disorders"; further mentioning that these syndromes have also been referred to as culture-bound or culture-reactive, and as ethnic or exotic psychoses. Some are rare and some may be comparatively common; many are acute and transient; which makes their systematic study particularly difficult. While acknowledging that these syndromes have diverse characteristics, they also have two common features: 1) They are not easily accommodated in established and international diagnostic categories. 2) Their initial description is in a particular population or cultural area and their subsequent association is with this community or culture.[20]

The ICD-10 has thus made cautious and tentative associations between cultural syndromes and recognized psychiatric categories, but problem again is that these are culturally specific. We argue that these are reported from other cultures too and are not exclusive [20]. The ICD-10 includes 12 frequently described 'culture-specific disorders', together with suggestions concerning their tentative placement in ICD categories: Amok (F68.8); Dhat (F48.8, F45.34); Koro (F48.8, F45.34); Latah (F48.8, F44.88); Nervios (F32.11, F48.0, F45.1); Pa-leng (F40.2); Pibloktoq (F44.7); Mixed dissociative disorders(F44.88); Susto 
(F45.1, F48.8); Taijinkyofusho (F40.1, F40.8); Ufufuyane (F44.3, F44.7); Uqamairineq (F44.88, G47.4); Windigo(?F68.8) DSMIV[21]. The DSM, hinted first at the need of including cultural items in its third version, DSM-III[22] and giving them room in DSM-IV.

The DSM-IV attempted to present them as innovative documents that included an outline for a cultural formulation (OCF) and a glossary of 25 culture-bound syndromes, formally admitted for the first time in a classification system. Without denying these features, what was not publicized, perhaps for being too obvious, was the fact that the additions were relegated to Appendix I of DSM-IV, the next-to-last in the thick volume, and that this was just a minimal portion of a substantial piece of scholarship.[23] DSM-IV-TR[24] In the DSM-IV-TR, culturebound syndromes were seen as "recurrent, locality-specific patterns of aberrant behavior and troubling experience that may or may not be linked to a particular DSM-IV diagnostic category". The following characteristics were seen as crucial for them: 1) indigenously considered illnesses or afflictions therefore a recognition within the society as a deviation from normal or healthy presentation. 2) Local names - the ascription of a specific local name to the experience of mental distress. 3) Symptoms, course and social response often influenced by local cultural factors. 4) Limited to specific societies or cultural areas. 5) Localized - therefore experiences that are not globally recognized or span different regions.

The conditional statement, that these syndromes "may or may not" be linked to a psychiatric diagnosis, makes clear that the relationship between the culture-bound syndromes and psychiatric disorders is complex and still needs considerable research. DSM-5 [21]. The DSM-5 discarded the concept of culture-bound syndromes with a preference for the term "cultural concepts of distress", which has been defined as "ways that cultural groups experience, understand, and communicate suffering, behavioral problems, or troubling thoughts and emotions". Consequently, three cultural concepts have been identified:

1) cultural syndromes: "cluster of symptoms and attributions that tend to co-occur among individuals in specific cultural groups, communities, or contexts and that are recognized locally as coherent patterns of experience",

2) cultural idioms of distress: "ways of expressing distress that may not involve specific symptoms or syndromes, but that provide collective shared ways of experiencing and talking about personal or social concerns",

3) Cultural explanations of distress or perceived causes: "labels, attribution, or features of an explanatory model that indicate culturally recognized meaning or etiology for symptoms, illness or distress".
Cultural concepts have four key features in relation to DSM-5 nosology:

1) There is seldom a one-to-one correspondence of any cultural concept with a DSM diagnostic entity; the correspondence is more likely to be one-to-many in either direction.

2) Cultural concepts may apply to a wide range of severity, including presentations that do not meet DSM criteria for any mental disorder.

3) In common usage, same cultural term frequently denotes more than one cultural concept. 4) Cultural concepts may change over time in response to both local and global influences. Interestingly, the DSM-5 emphasizes that all mental distress is culturally framed and acknowledges that different populations carry varying and culturally determined ways of communicating distress along with explanations of causality, coping methods and help-seeking behaviors.

\section{Trance-Cultural Psychiatry}

Culture-related specific syndromes are defined as psychiatric syndromes that are closely and significantly related to certain cultural features in their formation or manifestation of psychopathology. The clinical manifestations tend to be different from those of psychiatric disorders that fit within existing psychiatric classifications. Whether they are prevalent or infrequent in those areas is not as much an issue in determining whether special clinical attention is warranted as the importance of cultural factors in their formation and the significance of local people's reactions to them $[22,23]$.

Cultural influences on psychiatric syndromes can occur in at least six distinct ways:(1) pathogenic effect (cultural influence on the formation of a disorder); (2) psycho-selective effect (culture selecting certain coping patterns to deal with stress); (3) psycho-plastic effect (culture modifying the clinical manifestation); (4) patho elaborating effect (culture elaborating mental conditions into a unique nature); (5) psych facilitating effect (culture promoting the frequency of occurrence); or (6) psycho reactive effect (culture shaping folk responses to the clinical condition).

If the cultural effect is merely a psycho reactive one, there will be an argument as to whether or not it will meet the criteria for a culture related specific syndrome, because, in addition to their often being nonspecific or unique pathological condition involved, the cultural impact is secondary in nature, merely interpreting and labeling the phenomenon. Cultural factors impact every kind of psychopathology to some extent -whether or not it is predominantly psychological or biological in nature (or a minor or major psychiatric disorder). However, unless the cultural impact is very significant and deserves special attention, 
there is no point in identifying and labeling any pathology as a 'culture-related specific syndrome' [24,25].

\section{Importance of Culture for Psychiatric Diagnosis}

1. To avoid misdiagnosis-: The variation in cultural symptoms and in explanatory models associated with these cultural, concepts may lead the clinicians to misjudge the seriousness of a problem or entertain a wrong diagnosis.

2. To obtain useful clinical information-: Culture variations in symptoms and attributions may be associated with particular features of risk, resilience and outcome.

3. To improve clinical rapport and engagement-: Knowing the language of the patient both linguistically and also in terms of his prevailing concepts can prove helpful in communication, and facilitate negotiation which leads to higher retention and adherence.

4. To improve therapeutic efficacy-; culture can influence the physiological mechanism of disorder, which needs to be understood and addressed to improve clinical efficacy.

5. To guide clinical research-: locally perceived connection between culture concepts may help identify pattern of comorbidity and underlying biological substrates.

6. To clarify the cultural epidemiology-culture concepts of distress are not approved uniformly by everyone in a particular culture. Distinguishing syndromes, idioms and explanation provides an approach for studying the distribution of culture features of illness across setting and regions and over time.

7. It also suggests questions about cultural determinations of risk cause and outcome in clinical and community settings to enhance the evidence base of culture research.

Once the disorder is diagnosed, the culture terms and explanation should be included in case formulation; they may help clarify symptoms and etiological attribution that could otherwise be confusing [26-30].

\section{Conclusion}

The influence of culture on mental health condition has been seen through the study of culture-related specific syndromes. The impact of culture on specific syndromes that are strongly related to culture is easier to be seen. However, it needs to be recognized that culture-related syndromes are merely the tip of the iceberg. The diverse cultural and ethnicity of the world is a challenge to the field of mental health towards the development of cross culture approach. Therefore the focus should not be on the clinical manifestation but the evaluations should be made from the view of cultural aspects too. The researchers should be focused on the phenomena of cultural nature. If the analysis of culture is to be merged with psychopathological and behavioral analysis in comparative studies then the cross culture research should be evidenced anthropologically.

\section{Reference}

1. Tomlinson J (1999) Globalization and culture. University of Chicago Press, Chicago, USA.

2. Kleinman A (1978) Concepts and a model for the comparison of medical systems as cultural systems. Social science \& Medicine. Part B: Medical Anthropology 12(2): 85-93.

3. Bacallao ML, Smokowski PR (2007) The costs of getting ahead: Mexican family system changes after immigration. Family Relations 56(1): 52-66.

4. Gautam S, Jain N (2010) Indian culture and psychiatry. Indian journal of psychiatry 52(1): S309-S313.

5. Trujillo M (2001) Culture and the organization of psychiatric care. Psychiatric Clinics of North America 24(3): 539-552.

6. Tseng WS (2001) Handbook of cultural psychiatry. International Review of Psychiatry 14: 71-73.

7. Chowdhury AN, Nath AK, Chakraborty J (1993) An atypical hysteria epidemic in Tripura, India. Transcultural psychiatry 30(2): 143-151.

8. Eisenberg L (1977) Disease and Illness Distinctions between Professional and Popular Ideas of Sickness. Culture, Medicine and Psychiatry 1(1): 9-23.

9. Boyd KM (2000) Disease, Illness, Sickness, Health, Healing and Wholeness: Exploring Some Elusive Concepts. Medical Humanities 26(1): 9-17.

10. Chowdhury AN (2012) Culture, psychiatry and cultural competence. In Mental Illnesses-Understanding, Prediction and Control. InTech.

11. Sam DL, Berry JW (1995) Acculturative stress among young immigrants in Norway. Scandinavian journal of psychology 36(1):10-24.

12. Cheetham RW (1983) Deculturation as A Precipitant of Parasuicide in an Asian Group. South African Medical Journal 63(24): 942-945.

13. Bhugra D, Becker MA (2005) Migration, Cultural Bereavement and Cultural Identity. World Psychiatry 4(1): 18.

14. Kroeber AL (1940) Stimulus Diffusion. American Anthropologist 42(1): $1-20$.

15. Grier WH, Cobbs PM (2000) Black rage. Wipf and Stock Publishers, USA.

16. Sadock B (2009) Comprehensive textbook of psychiatry-Kaplan and Sadock's. Culture Bound Syndromes 27: 2519-2538.

17. Berry JW, Kim U, Minde T, Mok D (1987) Comparative studies of acculturative stress. International Migration Review 21: 491-511.

18. Hughes CC (1983) Culture-bound or construct-bound? In The culturebound syndromes Netherlands, pp. 3-24.

19. Guarnaccia PJ, Rogler LH (1999) Research on culture-bound syndromes: New directions. American Journal of Psychiatry 156(9): $1322-1327$.

20. Ventriglio A, Ayonrinde O, Bhugra D (2016) Relevance of culture-bound syndromes in the $21^{\text {st }}$ century. Psychiatry and clinical neurosciences 70(1): 3-6.

21. World Health Organization (1992) The ICD-10 classification of mental and behavioural disorders: clinical descriptions and diagnostic guidelines. 
22. American Psychiatric Association. (1994) Diagnostic and Statistical Manual of Mental Disorders, $4^{\text {th }}$ edn. American Psychiatric Association, Washington, USA.

23. Tseng WS (2006) From peculiar psychiatric disorders through culturebound syndromes to culture-related specific syndromes. Transcultural Psychiatry 43(4): 554-576.

24. Ventriglio A, Ayonrinde O, Bhugra D (2016) Relevance of culture-bound syndromes in the 21st century. Psychiatry and clinical neurosciences 70(1): 3-6.

25. American Psychiatric Association. (1980) Diagnostic and Statistical Manual of Mental Disorders, $3^{\text {rd }}$ edn. American Psychiatric Association, Washington, USA.

26. Alarcon RD (2014) Cultural inroads in DSM-5. World Psychiatry 13(3) 310-313.

This work is licensed under Creative Commons Attribution 4.0 License

DOI: 10.19080/PBSIJ.2017.05.555675
27. American Psychiatric Association (2000) Diagnostic and Statistical Manual of Mental Disorders, IV-TR, American Psychiatric Association, Washington, USA.

28. American Psychiatric Association (2013) Diagnostic and Statistical Manual of Mental Disorders, $5^{\text {th }}$ edn. American Psychiatric Association, Washington, USA.

29.Zachar P, Kendler KS (2007) Psychiatric disorders: a conceptual taxonomy. American Journal of Psychiatry 164(4): 557-565.

30. Adams GR, Marshall SK (1996) A developmental social psychology of identity: Understanding the person-in-context. Journal of adolescence 19(5): 429-442.

Your next submission with Juniper Publishers
will reach you the below assets
- Quality Editorial service
- Swift Peer Review
- Reprints availability
- E-prints Service
- Manuscript Podcast for convenient understanding
- Global attainment for your research
- Manuscript accessibility in different formats
( Pdf, E-pub, Full Text, Audio)
- Unceasing customer service
Track the below URL for one-step submission
https://juniperpublishers.com/online-submission.php

